\title{
A Case Study of Mobile Technology-enabled English Language Learning: The Amazon Kindle e-Reader Initiative in Palestine
}

\author{
http://dx.doi.org/10.3991/ijim.v8i3.3770 \\ K. Shraim \\ Palestine Technical University - Kadoorie, Palestine
}

\begin{abstract}
The proliferation of increasingly interactive ereader devices such as the Amazon Kindle represents an opportunity to explore their evolving pedagogical value. This study aims to investigate how use of the Kindle can enhance individuals' English language learning-more specifically their attitudes, reading comprehension, vocabulary development and pronunciation performancein the context of informal and lifelong learning in Palestine, and to explore the further potential of scaling up the use of e-readers at a national level. At the piloting stage of this initiative, the study operated at two levels (micro and meso) of the M3 evaluation framework. Mixed methods were used: qualitative data were obtained through a case study of the practices and perceptions of two teachers in two classrooms in the Qalqilia center and quantitative data were collected through a survey of $\mathbf{1 1 4}$ learners. The study shows that the Kindle's technological affordances are effective in creating a flexible, authentic and interactive environment for English language learning, provided that teachers change their teaching methods to take full advantage of the features of mobile technologies to create innovative learning approaches aligned with the needs of the e-generation. It was also found that despite some concerns with the usability issue, attitudes towards learning English changed positively and learners' vocabulary and pronunciation improved.
\end{abstract}

Index Terms-e-Reader devices; Amazon Kindle; Mobile Assisted English Language Learning; M3 evaluation framework

\section{INTRODUCTION}

e-Book readers, simply called e-readers, are innovative and increasingly popular mobile devices for reading digital texts, especially books [1]. Available models include: Kindle (Amazon), Sony Reader, Nook (Barnes and Noble), iPad, iPhone (Apple) and other smartphones. Currently, the Kindle is the model most frequently used to read e-books. 1 The Kindle Mobile Learning Initiative, launched globally in June 2012, is a public-private partnership between Amazon.com and the US government whose purpose is to create a global e-reader program with famous American novels, fiction and non-fiction stories, spelling and vocabulary games. It is intended to expand English language learning opportunities worldwide in new ways [2].

Reading has always been recommended for sharpening and boosting language knowledge and with e-reader devices like the Kindle, the process of learning English is

\footnotetext{
${ }^{1}$ http://ebook-reader-review.toptenreviews.com/.
}

becoming faster and more enjoyable than is the case with paper-book reading [3]. Among the most noted affordances of e-readers and mobile technologies generally are interactivity, portability and connectivity. eReaders allow learners to interact with the text in new ways. This interaction gives learners the opportunity for instant oral-text narration, word-pronunciation, definitions in a built-in dictionary and other useful educational tools for highlighting, bookmarking, note-making, searching feature, games, music, sound effects and other effective features for more advanced educational reading [4]. Many e-readers additionally contain multimedia elements and animated content that support the reading of the text and help readers visualize meaning and comprehend more easily [5]. Portability is another important advantage; eReaders are small and light, which means that they can be carried anywhere, allowing learners to access learning resources and so to undertake learning activities whenever and wherever they wish [6]. The wireless connection through the built-in $\mathrm{Wi}-\mathrm{Fi}$ and $3 \mathrm{G}$ network of the advanced mobile technologies offers easy connectivity, providing language learners with opportunities to be involved in meaningful real-context interactions, especially in informal out-of-class situations [7]. Connecting formal and informal learning is particularly beneficial for language learners who find themselves in a natural English-speaking environment [8].

English competencies are critical for learners' academic and lifelong success. Research indicates that there is inadequate language proficiency among Palestinian learners for various reasons, such as the negative attitude of students towards the second language, the lack of opportunity to practice the language in authentic situations, the shortage of well-trained English language teachers and the tendency to teach towards grammatical accuracy rather than fluency [9]. To increase the English language proficiency of Palestinian students, in 2006 the Ministry of Education and Higher Education (MEHE) made English language learning a compulsory subject from grade one of schooling. One result, however, has been a severe shortage of well-trained English teachers. While in-service provision has increased since the introduction of English in grade one, lack of appropriate training is still seen as problematic by many teachers, as they have not been exposed to communicative language teaching approaches. Evidence has shown that learners have low levels of English proficiency and many take private lessons, which are not affordable by all families, especially the underprivileged. To counter negative attitudes toward English and motivate digital natives who 
are well connected to electronic devices, the MEHE therefore needs a more flexible approach to English language support and greater innovation in using new technologies to deliver English language.

AMIDEAST $^{2}$ and the British Council are organizations currently active in Palestine, delivering English language and professional training programs to enhance the English proficiency of both students and English teachers. One interesting program is ACCESS, funded by the US Department of State Bureau of Educational and Cultural Affairs, via the US Consulate General in Jerusalem and in partnership with AMIDEAST. ACCESS provides Palestinian high school students, aged 14-16, with 240 hours of English language training. The purpose of the program is to increase the English language skills and capabilities of Palestinian youths whose families are unable to afford a substantive, sustained program of private English language training. It also seeks to create a spirit of community involvement and develop leadership skills among the participants. Since its inception in 2004, more than 7500 Palestinian students have benefited from ACCESS. This is a call to action across the nation to bring all students up to English proficiency. One way of tackling the situation is through the integration of new technologies. In 2013, AMIDEAST began piloting the use of Kindles in Palestine as part of the ACCESS program. 470 Kindle Keyboard 3G devices were distributed by AMIDEAST to learners in 16 districts of Palestine for six weeks. The purpose of the project was to gauge how well learners coped with using e-readers to improve their English language in the Palestinian environment. Therefore, it is important to evaluate the Kindle's affordance of pedagogical appropriateness by investigating actual English language learning and the conditions under which it occurred.

Mobile Assisted Language Learning (MALL) is an emerging and rapidly evolving research field, according to Viberg and Grönlund [10], who report that several studies have indicated positive attitudes towards the use of various mobile technologies to facilitate language acquisition in general, suggesting that they could be used to enhance English proficiency in particular. However, very little attention has been devoted to investigating how e-readers can help to improve second language acquisition in the out-of-class, real-world context. The overall aim of the present study is therefore to investigate how Kindle use can enhance individuals' English language learning and more specifically their attitudes, reading comprehension, vocabulary development and pronunciation performance in the context of informal and lifelong learning within the overall Palestinian context; it also aims to explore the potential for scaling up e-reader use in MALL at a national level.

The paper first reviews the relevant literature, highlighting the importance of the e-reader to enable English language learning. Section 3 next describes the research design and the data collected, while section 4 discusses the main findings of the research. Finally, conclusions are drawn and future research opportunities suggested.

\footnotetext{
${ }^{2}$ AMIDEAST is a US non-profit organization that works to strengthen mutual understanding and cooperation between Americans and the peoples of the Middle East and North Africa (www.amideast.org).
}

\section{LITERATURE REVIEW}

With the recent popularity of e-readers among individuals and institutions, researchers continue to study their effects on learning [11]. A number of studies illustrate their effectiveness in improving learners' attitudes to English reading, their reading comprehension and vocabulary acquisition [1]; [5]; [12]; [13]; [14]; [11]; [15].

Among many studies of e-reader use and reading attitudes[1]; [11]; [15]; [16], Miranda et al. [1] studied 199 low-reading-ability middle school students in Dallas-Fort Worth, Texas, who were given the option to use a Kindle during their scheduled sustained silent reading time for two months. The researchers found that e-readers had a strong potential to entice reluctant readers to engage and read more. Overall satisfaction with the Kindle program was high among the participants and their two teachers.

In a descriptive case study, Anderson [16] observed and interviewed 15 third-grade public school students to explore their experiences using e-readers. Participants were observed for 30 minutes each day during independent reading time in the classroom and met with the researcher for 45 minutes after school, weekly for six weeks, to engage in conversations about the books they were currently reading on their Kindles. The findings provide evidence that learners had increased reading engagement, motivation to read, positive attitudes toward reading, reading volume, and ease of reading using the ereaders compared to regular books.

Huanga [15] also investigated students' perceptions of e-readers. The participants were 67 first-year university students drawn from two sections of an intermediate English-as-a-foreign-language (EFL) reading course in northern Taiwan. Students provided positive feedback on e-readers' potential to cultivate better reading habits and increase motivation; they also perceived them as being more available, portable, and eco-friendly than print-based texts.

A recent study of ninth-grade students in a school in Western Pennsylvania found that using Kindles in English-language arts classes helped to excite and engage students in reading [11]. The results also provided insight into students' emotional feelings and perceived values regarding using e-readers in learning. Matis [11] concludes that if educators are to begin to tackle the complex issue of demotivation to read, they must promote new literacy technologies, specifically, e-readers.

In England, Goodwyn [17] studied English teachers' perceptions of the potential value of e-readers in teaching English. A majority of teachers welcomed e-readers as a dynamic element within the reading environment, with particular potential to enthuse reluctant readers and those with special or linguistic needs. English teachers also believed that reading using this form of technology appealed to the 'e-generation' and might succeed in making reading 'cool'. Goodwyn [17] concludes that this form of technology is likely to be rapidly adopted in classrooms.

In addition to the influence on teachers' and learners' attitudes, researchers have explored the enhancement of reading comprehension, vocabulary and pronunciation. According to Grimshaw et al.[5], the rich multimedia features in many newer e-readers, such as audio narration, sound effects and animation, support the reading of the 
PAPER

A Case Study of Mobile Technology-enabled English Language Learning: the Amazon Kindle...

text by aiding comprehension and visualization of meaning. Text-to-speech features also help learners to pronounce particular words and understand syntax. An added advantage is a degree of privacy, as many learners are reluctant to ask a teacher for help in a classroom setting [5]. Miranda et al. [1] found that this feature was very useful to students whose first language was not English, as it seemed to help them gain confidence in English reading and speaking.

In a three-week observational case study of two second-grade students (one a native Chinese speaker) in a US public school, Larson [12] examined how Kindles can promote physical interaction through engagement with text. The two students used several functions such as making font adjustments, activating text-to-speech, highlighting passages, using the built-in dictionary, performing keyword searches and adding personal notes and questions in response to what they were reading through the 'My Clippings' feature. Larson [12] concludes that the interactive features of e-readers encourage children's reading.

Yannick [18] explored the effects of extensive reading of e-books on different aspects of foreign language ability, including general reading ability and lower-level linguistic ability, among 31 Japanese university freshmen. While linguistic abilities like spelling and morphosyntax did not improve significantly, learners' reading ability did improve greatly.

Another university-level study, of a two-semester pilot program in Introductory English courses in California, focused on whether e-readers enhanced student learning [13]. The researchers found the Kindle to be highly supportive of the course objectives such as learning new vocabulary and writing reflective and structured essays. Students reported that functions such as instant access to a dictionary, adapting font size to needs, listening to music while reading and text-to voice were helpful study aids. To improve writing and engagement with text, students used My Clippings to store their notes and highlights, providing a body of material to use in writing the assigned academic essay.

In a recent ten-week study, Chen et al. [14] investigated the effects of extensive reading of e-books on 89 Taiwanese tertiary level EFL students' attitude, reading comprehension and vocabulary. The experimental group exhibited significantly better reading attitude, reading comprehension and vocabulary growth than the control group. The authors conclude that having a positive attitude towards e-books, learners may be motivated towards the new experience of reading in second language.

In a recent ten-week study, Chen et al. [14] investigated the effects of extensive reading of e-books on 89 Taiwanese tertiary level EFL students' attitude, reading comprehension and vocabulary. The experimental group exhibited significantly better reading attitude, reading comprehension and vocabulary growth than the control group. The authors conclude that having a positive attitude towards e-books, learners may be motivated towards the new experience of reading in second language.

In developing countries, a pilot study conducted in 2010 by WorldReader aimed to investigate the effects of introducing Kindles into Ghanaian public schools. 481 students were given Kindles with a local content created by digital conversion of 82 Ghanaian books in both
English and native languages. The researchers found that using Kindles increased students' enthusiasm for reading as a lifetime habit and had a positive effect on reading performance. Further, while conventional books are scarce in such rural settings, student and teachers had instant access to reading materials and teaching resources, facilitating and significantly accelerating the learning process beyond the allotted class time [19].

Several studies have also compared reading comprehension in digital and paper formats [4]; [5]; [20]; [21]. Their results indicate no significant difference in overall reading comprehension abilities. However, students indicated a higher level of enjoyment while reading digital texts and the e-readers motivated students to engage in reading. According to Schugar et al. [20], there is immense potential for these devices to positively impact students' active and critical reading skills, but teachers must first learn how to better incorporate them into their pedagogy and students must also learn how to use them. Chen et al. [14] suggests that certain tasks may help the development of reading comprehension and vocabulary growth, such as identifying key phrases, guessing word meaning from context, connecting the contents of the reading selection to current or past realworld events and experiences, and writing reflections on the text in weekly individual reading journals.

Other studies have focused on the usability of e-reader features. Pilot programs with Amazon Kindle DX ereaders have been initiated at seven US universities to study their viability in replacing or complementing the traditional texts used in university courses and to explore their environmental sustainability [22]. Students at Princeton University were positive about using the ereader but found drawbacks in using the highlighting, note-taking and navigating features [23], while students at Reed College reported strong optimism towards the device and its ability to have a positive effect on comprehension. The ability to adjust text size and style was reported as a positive benefit [24]. Students at Ohio State University reported frustration and complications when formatting etext citations for research papers when reading documents on the e-reader, but appreciated the devices for their portability [25]. In the UK, Nie et al. [26] assessed the potential of Sony PRS-505 readers to support distance learning at the University of Leicester and to address some of the challenges faced by learners on two master's programs in Occupational Psychology and one in Teaching English to Speakers of Other Languages. The evidence suggests that the students' learning experiences improved because e-readers enhanced flexibility in curriculum delivery to accommodate the mobile lifestyle of learners, improved efficiency in the use of fragmented study time, promoted new strategies for reading course materials, and reduced costs.

Most studies to determine the usefulness of e-readers in higher education settings have adjudged them more useful and appropriate for leisure reading than for study purposes [23]; [24]; [25]; [26]; [27]. Gregory [28] found that usage and attitudes towards e-readers varied with the type of reading material. According to Ahlroos and Hahto [29], reading a novel differs substantially from reading a textbook, as in leisure reading the text usually advances linearly, while reading for study and research purposes involves browsing, glancing, seeking and re-reading. 
Little research has yet examined e-readers in developing countries in relation to EFL. To fill this gap, this research investigated how use of the Kindle can enhance individuals' English language learning-more specifically, attitude, reading comprehension, vocabulary development and pronunciation performance-in the context of informal and lifelong learning in Palestine.

\section{Methodology}

Vavoula and Sharples [7] propose a three-level framework for evaluating mobile learning, comprising a micro level concerning usability, a meso level addressing the learning experience, and a macro level assessing integration within existing educational and organizational contexts. This study applies only the micro and meso levels, because at this stage of the research, evaluation of the longer-term impact of the new technology on established learning practices is not yet possible. Evaluation at the micro level includes the technological usability of the Kindle, focusing on the ease and attractiveness of learning to use it under certain conditions; at the meso level, it explores learners' attitudes and learning experiences. The research focuses specifically on the following questions:

- How usable are the Kindle's technological attributes for learners?

- How do the Kindle's technological attributes improve English language learners' reading comprehension, vocabulary and pronunciation?

- Does the Kindle affect learners' attitudes towards learning English?

- In the context of Palestine, what are the main considerations for the potential scaling-up of ereaders and other mobile technologies at a national level?

Data were collected over a period of time via discrete task observations, interviews and surveys.

qualitative data were obtained through a case study of the practices and perceptions of two teachers in two classrooms in the Qalqilia center. Quantitative data were gathered in March 2013 using a questionnaire survey comprising 28 questions on the usability of Kindle features, learners' attitudes, learning experiences and general information on participants, who were also asked to comment on the questionnaire. The quantitative data from the survey were analyzed using descriptive statistical techniques and triangulated with the qualitative data.

\section{RESUlts AND DisCUSSION}

\section{A. Observation}

The researcher attended three five-hour sessions of each of two Saturday classes (17-18 students) to observe how learners used the e-reader's features and what teaching and assessment methods facilitators used in the two classes. The two facilitators developed an activity plan for using the same teaching methods and a rubric in three main categories: reading comprehension, building vocabulary and pronunciation performance. The facilitators used the rubric in the first session and at the end of six weeks to assess learners' progress. Comparing the pretest and posttest scores revealed that vocabulary and pronunciation scores had risen, while reading comprehension scores had fallen slightly and not significantly. Thus, there is evidence that in this short time the Kindle enabled a significant improvement in learners' vocabulary and pronunciation.

\section{B. Interviews}

When the two facilitators were interviewed regarding their observations and impressions of using the Kindle, facilitator A was very satisfied with how the learners began to use the dictionary feature of the Kindle, looking up words that they did not understand in context. The facilitator also confirmed that over the course of the project, learners had improved their sentence constructions, and their speaking fluency and articulation. She felt that the Kindle stimulated learners' interest and encouraged them to read.

Facilitator B observed that the majority of learners were more engaged by reading on the Kindle than from a print book. He noted that they usually enjoyed turning on the text-to-speech feature, allowing them to hear the story being read by a native English speaker while following the written words, thus becoming acquainted with correct pronunciation. These results are consistent with those reported by Grimshaw et al. [5] and Miranda et al. [1], and with the finding that for both facilitators and learners who are not native English speakers, text-to-speech is very useful in improving phonemic awareness and gaining confidence in reading and speaking English.

Overall, facilitators agreed that for the most part, learners demonstrated increased levels of excitement around reading through Kindle and that less motivated students, who manifested major anxiety and negative attitudes towards English, increased their level of engagement and improved their performance. However, facilitators saw the Kindle as a supplement to printed books, not a replacement. One commented: "The ultimate success of using Kindle depends on pedagogy rather than technology... Teachers should believe in the pedagogical soundness of the digital component of the Kindle ... If it is used with effective instruction and solid pedagogy, learners will improve their English". Thus, a pressing concern is how teachers motivate their students by changing their teaching methods while integrating technologies to meet the demands of an e-generation who want to be "connected" to new technologies [11].

Both facilitators intend to continue using e-readers and other mobile technologies to enable English language learning. However, not all language teachers are expected to be willing and able to do so. To help teachers effectively leverage new mobile technologies for educational purposes, so that innovative teaching might stimulate the whole learning environment, teachers need to have positive attitudes towards these technologies and more training in incorporating them into their work. This finding is consistent with those of Larson [12], Schugar et al. [20] and Chen et al. [14].

Both facilitators expressed concern with technical challenges such as the unreliability of Wi-Fi and $3 \mathrm{G}$ networks in Palestine and the difficulty in using some Kindle tools. For facilitator A, the most challenging part of implementing the pilot was limited connectivity. While the Internet is commonplace in developed countries today, access remains patchy in developing countries. In Palestine, for example, free $3 \mathrm{G}$ web-browsing is not available. $3 \mathrm{G}$ is an important requirement for the successful implementation of mobile learning, and it will 
be difficult to meet such requirements at present. Facilitator B highlighted another challenge regarding the digital divide: financial constraints will make it difficult to provide e-readers for all learners. According to Miranda et al.[1], schools do not have the financial means to provide all students with e-readers and not all families can afford to buy a device for each child. In Palestine the problems of meeting the needs of the new generation and bridging the digital divides among students and between school and home are particularly difficult, as the average family has seven members, with at least three children at school at the same time.

Therefore, policymakers need a clear strategy for scaling these initiatives at the national level, raising awareness, training and creating an enabling environment to convince and enable teachers to adopt them gradually in their lessons. There is also a need to collaborate with international organizations, private firms and civil society bodies to provide devices and improve the infrastructure.

\section{Questionnaire}

Data from 114 completed questionnaires were analyzed using descriptive statistical techniques. All learners were around the age of 15 years. Of those who responded to the survey, 64\% were female. Participants were all West Bank residents of middle socioeconomic status; $45 \%$ of students' fathers and $35 \%$ of mothers had university degrees. All participants had access to laptops and mobile phones at home and nearly 35\% used smartphones and iPads, but none had previous exposure to e-readers. Only $7.8 \%$ of learners sometimes spoke English at home with their families. The fact that they did not regularly use English outside school may have affected their English competency. During the piloting period, two-thirds normally used their Kindle for around 30 minutes each day.

\section{1) Usability}

When asked about the user-friendliness of the Kindle tools, $62 \%$ of respondents described the devices as cumbersome. Some learners reported many unsatisfactory aspects of the interaction with the texts in the form of navigation, bookmarking, annotation and clipping. These results support the observation and interview finding that learners had some difficulties with the devices, particularly when posting notes to social networks like Facebook and Twitter directly from My Clippings and using the keyboard and the 5-way controller for flipping between pages, navigation and highlighting.

On the other hand, most respondents considered the Kindle comfortable for reading even in bright sunlight: $90 \%$ agreed or strongly agreed that there was no annoying glare, unlike reflective tablet and smartphone screens. The most appreciated feature was the long battery life: $93 \%$ agreed or strongly agreed that the Kindle would remain charged for up to several weeks, unlike tablets that need to be charged each night. This is very important in Palestine, where the electricity supply is frequently interrupted, especially in disadvantaged areas such as Gaza.

When asked about content issues, participants tended to agree that an obstacle to using the Kindle was inadequate availability of stories and content irrelevant to their culture. AMIDEAST uploaded only twelve American stories to the devices and learners could not download books from Amazon because of licensing issues. Although given the opportunity to broaden their understanding of American culture, two-thirds indicated that they would prefer to read novels with Arab settings. Seventy-nine percent of learners also reported feeling confused by English vocabulary and indicated that they needed a builtin English-Arabic dictionary. Providing learners with both first and second language input during reading is effective in enhancing vocabulary acquisition.

Finally, $87 \%$ of participants were unsatisfied with the lack of multimedia functionality. The new generation tends to be interested in books with colored content, photos, sound and video. Multimedia functions also allow learners to record their own voices and compare them with an ideal pronunciation to help them correct the pronunciation of unfamiliar words and to improve their overall pronunciation[18]. However, this and some other criticisms would be less relevant for the current Amazon Kindle Fire HDX. According to Ahlroos and Hahto [29], technical specifications change rapidly and the new models are more refined and more likely than the Kindle $3 \mathrm{G}$ to meet usability needs; for instance color, touch screens and multimedia are becoming available.

\section{2) Attitudes towards Kindle features}

Respondents found the Kindle to have a number of interesting features, creating an on-demand flexible learning environment. Their most obvious advantage is ubiquity: $78 \%$ of learners valued the ability of the small, light device to store hundreds of books, with a handy web browser, allowing them to access authentic English language resources anytime and anywhere. Kindle devices were seen as a repository of varied content (books, newspapers, magazines, blogs, documents), bringing otherwise inaccessible resources within reach. Four-fifths of respondents agreed or strongly agreed that they liked learning on portable devices at their own pace without restriction to specific schedules or physical classrooms. This flexibility motivated them to engage in deep reading, a finding shared with Anderson [16]; Noble [25] and Nie et al. [26].

Learners considered the Kindle to be responsive, with interesting features for enhancing reading comprehension. Interaction with the text, such as highlighting, bookmarking, note-taking, listening to music and searching for a word or phrase while reading stories, newspapers and magazines, was perceived as very or somewhat important by two-thirds of respondents. According to Miranda et al.[1], interacting with text allows learners to establish comprehension and improve their skills in understanding, predicting, and critically analyzing what they read. Those who were dissatisfied with text interaction blamed the lack of multimedia, being uncomfortable with text alone, or complained of technical difficulties in using features such as note-taking.

Another important practical feature of the Kindle is the range of linguistic resources such as dictionary, text-tospeech, searching and games. $84 \%$ of learners agreed that the built-in dictionary function helped them define and pronounce unfamiliar words. Being given the correct phonetic form of unknown words makes developing new vocabulary very effective in promoting reading comprehension and general reading ability [14]. Some learners also reported that building vocabulary helped to develop their ability to write original short stories. Facilitators confirmed that those learners showed 
significant improvement in their writing skills, especially in clarity, conciseness and vocabulary-building.

The power and convenience associated with text-tospeech was also highly valued: an overwhelming $94 \%$ of respondents agreed that text-to-speech was very important for Palestinians, as listening to native English speakers was invaluable in improving their English accent. This feature also allowed them to revisit the reading as often as required, so that they could practice pronunciation on their own, reducing stress and anxiety, and boosting confidence. This finding supports the facilitators' observations and is consistent with the assessment of Miranda et al. [1] that text-to-speech helps students who struggle or lack confidence by giving them access to text that may be too difficult on the page alone.

Additionally, Kindle comes with free games like Every Word, Grid Detective and My Checklist, and learners can download others. Over $84 \%$ of learners agreed that learning English words while playing games was fun and interesting, and enabled them to enrich their English. Many learners commented that incorporating games with Kindle made them more highly engaged and enthusiastic about reading for longer periods of time.

Kindle integrates a communication platform that supports effective collaboration including blogs, social networks and emails. For 21 st-century learners, the ability to share their thoughts with peers and teachers, by posting meaningful passages to social networks like Facebook and Twitter directly from Kindle, proved useful [16]. Over two-thirds of respondents agreed that working with their peers and sharing their reflections helped them improve their English proficiency and develop skills in communication, critical analysis, note-taking and summarizing, writing and constructing sentences. This is consistent with Larson's finding [12] that My Clippings provided a valuable way for middle-school students to demonstrate the reflection that must accompany meaningful reading. Those respondents who disagreed preferred oral communication or had difficulty in using My Clippings.

3) Overall experience

Overall, almost two-thirds of learners preferred ereaders to printed books, $79 \%$ were willing to learn
English more often using mobile technologies and $81 \%$ indicated that their experience was worthwhile. The findings indicate that in Palestine, currently suffering conflict and crisis, where most parents cannot help their children to learn a foreign language, where class sizes average 50 and where opportunities to practice English outside school are limited, the Kindle would be appropriate for learners to take greater responsibility for their own learning of English.

To provide more meaningful feedback about their learning experiences, participants were asked to 'write up to five single words which best describe your overall experience of using Kindle as a tool for learning English'.

Responses were generally very positive, frequently mentioning the ubiquity attribute associated with Kindle. Forty-one respondents used the word 'flexibility', 21 'mobility' and 15 'handy'. This suggests that this generation likes learning on the move, anytime and anywhere, free from the classroom walls. In terms of content, the majority of users found the Kindle effective. The word 'interactive' occurred 33 times, with 28 respondents writing 'engaging', 24 'enjoying', 10 'cool', and 8 'fun'. Such opinions are obviously important in motivating learners to use e-readers and engage deeply in language learning. Usefulness is also reflected by 34 respondents using the word 'useful'. Twenty respondents wrote that the Kindle was 'practical', 17 wrote 'personalize', 15 'collaboration', 15 'unsatisfactory', 14 'game', 11 'text-to-speech', 9 'convenient', 6 'communication' and 7 'entertaining'.

In regard to accessibility, respondents had more mixed reactions. Thirty-five said it was 'easy', 28 saw the devices as being environmentally 'friendly' and 15 'accessible'. Conversely, some respondents had issues with the navigation, 23 saying that it was 'difficult', 15 'confusing', and 12 not 'easy to use', while 10 wrote 'lacks touch screen' and 11 commented that 'the screen was too small' and 'frustratingly slow'. There are clearly some accessibility issues that need to be considered for further development of the Kindle's features.

The responses are displayed as a word-cloud in FigureI. The larger the font size, the more common the word.

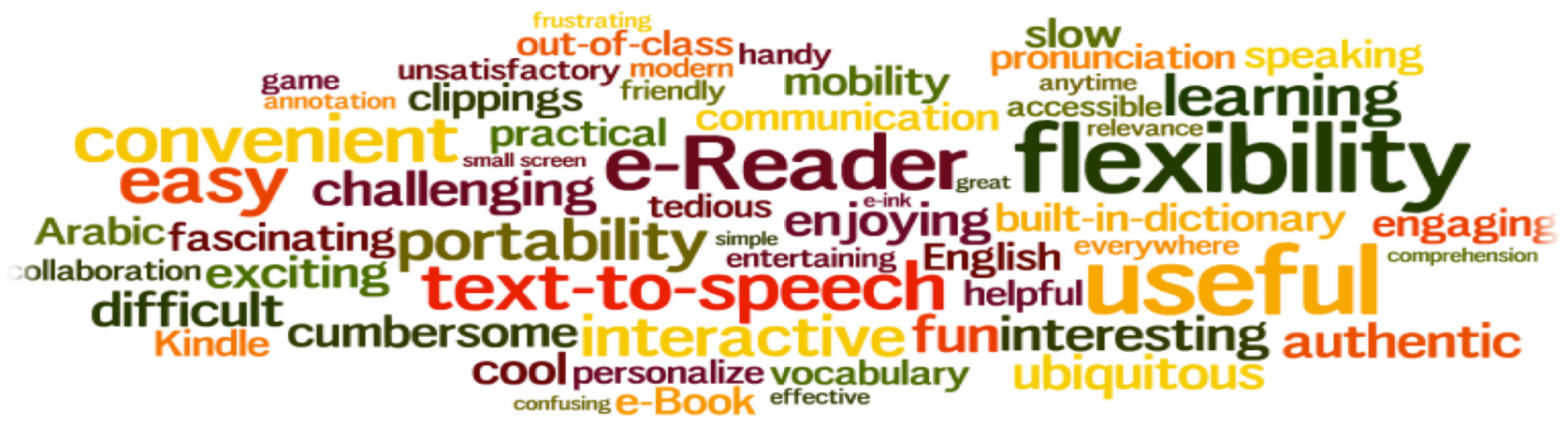

Figure 1. overall experience of using Kindle as a tool for learning English 


\section{CONCLUSION}

This study illustrates the potential use of mobile technologies, particularly the Amazon Kindle e-reader, to enable English language learning, more specifically learners' attitudes, reading comprehension, vocabulary development and pronunciation performance in the context of informal and lifelong learning in Palestine.

Learners found the technological affordances of the Kindle effective in creating a flexible, authentic, interactive and on-demand environment for English language learning. They valued several features including its portability, interaction with texts, linguistic resources (dictionary, text-to-speech, searching and games) and communication platform. There is evidence that these features have the potential to create a positive attitude towards learning English and to improve vocabulary and pronunciation. However, the ultimate success of using Kindles depends not only on technology but on innovative teaching methods and building a supportive learning environment, which seems to be a challenge to scaling up these initiative at the national level in the meantime.

Major limitations of the study were that the sample of participants was not geographically representative and the duration of the pilot was insufficient to determine the impact of the Kindle on language learning. Further research focusing on the longer-term effects of using emerging mobile technologies to enable English language learning in educational settings would be of great interest.

\section{REFERENCES}

[1] Miranda, T., Williams-Rossi, D., Johnson, K.A.\& McKenzie, N. 2011.'Reluctant readers in middle school: successful engagement with text using the e-reader', International Journal of Applied and Technology, Vol 1 No. 6, pp. 81-91.

[2] Owen, L.H. 2012.State Department speaks out on Amazon Kindle deal.Retrieved June 2, 2013, from http://paidcontent.org/2012/06/13/state-department-speaks-out-onamazon-kindle-deal/

[3] Spreeder 2013. Is Kindle The Solution To Learning English Fast? An Examination. Retrieved June 27, 2013, from http://www.spreeder.com/blog/is-kindle-the-solution-to-learningenglish-fast-an-examination/

[4] Wright, S., Fugett, A., \& Caputa, F. 2013.'Using E-readers and Internet Resources to Support Comprehension', Educational Technology \& Society, Vol 16 No.1, pp. 367-379.

[5] [5] Grimshaw, S., Dungworth, N., McKnight, C., \& Morris, A. 2007.'Electronic books: Children's reading and comprehension', British Journal of Educational Technology, Vol 38 No. 4, pp. 583599.

[6] Sharples, M. 2009. Methods for evaluating mobile learning, in Vavoula, G. N., Pachler,N. \& Kukulska-Hulme, A. (Ed.), Researching Mobile Learning:Frameworks,Tools and Research Designs, Oxford, Peter Lang Publishing Group, pp. 17-39.

[7] Vavoula, G., \& Sharples, M. 2009.'Meeting the challenges in evaluating mobile learning:A 3 level evaluation framework', International Journal of Mobile and Blended Learning, Vol 1 No.2,pp. 54-75. http://dx.doi.org/10.4018/jmbl.2009040104

[8] Kukulska-Hulme. A. 2009.'Will mobile learning change language learning?', ReCALL, Vol 21 No. 2, pp. 157-165. http://dx.doi.org/10.1017/S0958344009000202

[9] Keshta, A.S. 2013. 'Using Storytelling in Teaching English in Palestinian Schools: Perceptions and Difficulties', Education Journal, Vol 2, No. 2, pp. 16-26. http://dx.doi.org/10.11648/ j.edu.20130202.11

[10] Viberg, O. and Grönlund, Å. 2012. Mobile Assisted Language Learning: A Literature Review. In Specht, M., Sharples M. and Multisilta, J.(Ed.), mLearn, CEUR-WS.org, pp. 9-16.

[11] Matis, K.L. 2013. Using Electronic Reading Devices to Gauge Student Situational Interest in Reading: A Quantitative Study with
Ninth-Grade Language Arts Students. Unpublished Ph.D. Dissertation, Indiana University of Pennsylvania.

[12] Larson, L. C. 2010.'Digital readers: The next chapter in e-book reading and response', The Reading Teacher, Vol 64 No. 1, pp. 15-22. http://dx.doi.org/10.1598/RT.64.1.2

[13] Wines, J. \& Bianchi , J. 2010. Teaching and Learning with EReaders: A Case Study at CLU. educause. Retrieved August 27, 2013, from http://www.educause.edu/ero/article/teaching-andlearning-e-readers-case-study-clu

[14] Chen, CN., Chen, SC., Chen, SH.\& Wey, SC. 2013.'The effects of extensive reading via e-books on tertiary level EFL students' reading attitude, reading comprehension and vocabulary', TOJET: The Turkish Online Journal of Educational Technology, Vol 12 No. 2, pp. 303-312.

[15] Huanga, H. 2013.'E-reading and e-discussion: EFL learners' perceptions of an e-book reading program', Computer Assisted Language Learning, Vol 26 No.3, pp. 258-281. http://dx.doi.org/10.1080/09588221.2012.656313

[16] Anderson, T. L. 212. Examining Elementary Students' Use of Electronic Readers for Independent Reading. Unpublished Ph.D. Dissertation, The University of Tennessee.

[17] Goodwyn, A. 2013.'Machines to Think With? E-books, Kindles and English Teachers, the Much Prophesied Death of the Book Revisited', Changing English: Studies in Culture and Education, Vol 20 No.2 pp. 148-159.

[18] Yannick. J. (2007). M-Learning: A pedagogical and technological model for language learning on mobile phones, in Fong, J. and Wang F. L. (Ed.), Blended Learning, pp. 327-339.

[19] ILC Africa 2012. iRead Ghana Study Final Evaluation Report. WorldReader, Books for all. Retrieved February 24, 2013 from http://pdf.usaid.gov/pdf_docs/pnadz402.pdf

[20] Schugar, J. T., Schugar, H., \& Penny, C. 2011. 'A nook or a book: Comparing college students'reading comprehension level, critical reading, and study skills', International Journal of Technology in Teaching and Learning, Vol 7 No.2, pp. 174-192.

[21] Milone, M. 2011.Student comprehension of books in Kindle and traditional formats. Wisconsin Rapids, WI:Renaissance Learning. $\begin{array}{llll}\text { Retrieved April } & 20, & 2013 & \text { from }\end{array}$ http://doc.renlearn.com/KMNet/R0054730029120B5.pdf.

[22] Damast, A. 2010. 'E-Book Readers Bomb on College Campuses', BusinessWeek (June 11, 2010), 3.

[23] Cliatt, C. 2010. Kindle pilot results highlight possibilities for paper reduction. Retrieved May 28, 2013, from http://www.princeton.edu/main/news/archive/S26/64/38E35/index .xml?section=topstories

[24] Marmarelli, T., \& Ringle, M. 2010. The Reed College Kindle Study. Retrieved March 9, 2013 from http://www.reed.edu/cis/ about/kindle_pilot/Reed_Kindle_report.pdf.

[25] Noble, R. 2010. Amazon Kindle 2 pilot: E-readers in higher education. Retrieved April 18, 2013 from http://digitalunion. osu.edu/files/2010/09/Amazon-Kindle-2-Pilot.pdf

[26] Nie, M., Armellini, A. Witthaus, G. \& Barklamb, K. 2011.'How do e-book readers enhance learning opportunities for distance work-based learners?', Research in Learning Technology, Vol 19 No. 1, pp. 9-38.

[27] Clark, D. T., Goodwin, S., P, Samuelson, T., \& Coker, C. 2008. ‘A qualitative assessment of the Kindle e-book reader:Results from initial focus groups', Performance Measurement \& Metrics, Vol 9 No.2, pp. 118-129. http://dx.doi.org/10.1108/14678040810906826

[28] Gregory, C. L. (2008).'But I want a real book: An investigation of undergraduates' usage and attitudes toward electronic books', Reference and User Services Quarterly, Vol 47 No. 3, pp. 266273. http://dx.doi.org/10.5860/rusq.47n3.266

[29] Ahlroos, P.\& Hahto, J. 2012.'The e- Reader - an Educational or an Entertainment Tool? e-Readers in an Academic Setting',LIBER: the Association of European Research Libraries,Vol 21 No. 2. Retrieved September 8, 2013, from http://liber.library.uu.nl/index.php/lq/article/view/URN\%3ANBN \%3ANL\%3AUI\%3A10-1-113627/8376.

\section{AUTHOR}

K. Shraim is with Palestine Technical University Kadoorie, Palestine (kh_shraim@hotmail.com)

Submitted 17 April 2014. Published as resubmitted by the author 08 June 2014. 